\title{
RICHARD RORTY E A EMERGÊNCIA DA FILOSOFIA PÓS-ANALÍTICA NOS ESTADOS UNIDOS: TRANSFORMAÇÕES INSTITUCIONAIS E CRISE DISCIPLINAR, 1970-1980
}

\author{
Joaquim Elói Cirne de Toledo Júnior ${ }^{1}$ \\ Universidade de São Paulo (USP) \\ https://orcid.org/0000-0002-7125-4396
}

\section{RESUMO:}

Pode a história das instituições de ensino superior nos ajudar a compreender as causas de controvérsias filosóficas e os processos de mudança intelectual pelo qual velhos estilos intelectuais são substituídos por novos? Neste artigo, associo a emergência da filosofia pós-analítica nos Estados Unidos a partir da década de 1970 à reforma e expansão do sistema de ensino superior daquele país na segunda metade do século $\mathrm{XX}$, que afetou a filosofia enquanto disciplina acadêmica e profissão. Tomando como ponto de partida as reflexões de Richard Rorty a respeito do estado da disciplina no início dos anos 1980, mostro como seu diagnóstico de crise disciplinar, elaborado na forma de uma crítica filosófica aos pressupostos teóricos e metodológicos da filosofia analítica, é resultado de um processo mais longo e amplo de transformação das bases institucionais da vida filosófica profissional nos Estados Unidos.

PALAVRAS-CHAVE: Filosofia norte-americana contemporânea; Richard Rorty; Filosofia pós-analítica; Ensino superior.

\section{RICHARD RORTY AND THE RISE OF POST-ANALYTIC PHILOSOPHY IN THE UNITED STATES: INSTITUTIONAL CHANGE AND DISCIPLINARY CRISIS, 1970-1980}

\begin{abstract}
:
Can the history of higher education help us understand the causes behind philosophical controversies and the processes of intellectual change by which old intellectual styles are replaced by new ones? In this article, I relate the emergence of post-analytic philosophy in the United States in the 1970s to the reforms and resulting expansion of higher education in the second half of the $20^{\text {th }}$ century, which affected philosophy as an academic discipline and as a profession. Taking as my point of departure Richard Rorty's reflection on the state of the discipline in the early 1980s, I show how his diagnosis of disciplinary crisis, stated in the form of a philosophical critique of analytic philosophy's theoretical and methodological assumptions, are the outcome of a longer and broader process of transformation of the institutional bases of the professional philosophical life in the United States.
\end{abstract}

KEYWORDS: Contemporary American philosophy; Post-analytic philosophy; Richard Rorty; Higher education.

${ }^{1}$ Programa de Pós-Doutorado do Departamento de Filosofia da Faculdade de Filosofia Letras e Ciências Humanas da Universidade de São Paulo (FFLCH-USP), São Paulo - Brasil. E-mail: joaquim.toledo.jr@gmail.com.

TOLEDO JÚNIOR, Joaquim Elói Cirne de. Richard Rorty e a emergência da filosofia pós-analítica nos Estados Unidos: transformações institucionais e crise disciplinar, 1970-1980. Griot : Revista de Filosofia, Amargosa/Bahia, v.17, n.1, p.377-397, junho/2018. 
Em 1981, em simpósio sobre "A natureza e o futuro da filosofia" que integrou a programação do encontro anual da divisão leste da Associação Americana de Filosofia (APA), o professor Richard Rorty, da Universidade Princeton, apresentou "Philosophy in America today", seu diagnóstico sobre o estado da filosofia nos Estados Unidos na virada dos anos 1970 para os anos 1980 (RORTY 1982). Para Rorty, a narrativa então dominante nos meios filosóficos norte-americanos privilegiava uma versão heroica - e revisionista - da emergência da filosofia analítica no país que sugeria uma linha evolutiva que, do idealismo à análise, passando pelo pragmatismo, havia "procedido da especulação à ciência". Mesmo os pós-positivistas entre os analíticos - que haviam recebido de bom grado as críticas que figuras como Wittgenstein, Quine, Wilfrid Sellars e Thomas Kuhn (WitTgenstein 1969; Quine 1951; Sellars [1956] 1997; KuHn [1962] 2012) haviam dirigido, a partir dos anos 1950, aos pressupostos centrais do empirismo lógico - pareciam concordar com a ideia de que a filosofia naquele meio tempo se transformara em um "conjunto de problemas específicos, persistentes, que haviam sido abordados de forma desajeitada e pouco sofisticada em períodos anteriores, mas que agora são tratados com precisão e rigor inéditos" (RORTY 1982: 212). Havia um aparente consenso geral, pelo menos entre filósofos analíticos, de que a filosofia havia se tornado, nas últimas décadas, uma disciplina "científica e rigorosa" ou, ainda, de que os analíticos haviam realizado uma tarefa admirável ao estabelecer uma distinção clara entre, por um lado, a filosofia como "uma explicação, ou expansão, do conhecimento científico" como queria C. I. Lewis, por exemplo (TOLEDo 2015), e, de outro, a filosofia como "outra coisa" (idealismo, fenomenologia, existencialismo e outras formas de especulação metafísica). Em outras palavras, essa narrativa oficial a respeito das transformações da filosofia nos Estados Unidos entre sua profissionalização no final do século XIX e o triunfo da filosofia analítica a partir dos anos 1950 havia dividido o meio filosófico norte-americano entre "filosofia analítica" e "o resto".

Ainda segundo a leitura de Rorty, a filosofia analítica passou a dominar os departamentos de filosofia nos Estados Unidos no início dos anos 1950, e consolidou sua hegemonia com o estabelecimento de uma nova orientação curricular nos cursos de pós graduação a partir dos anos 1960 que dispensava a leitura de "heróis das gerações anteriores" como Dewey e Whitehead e o contato com a história da filosofia, e "atribuía ao estudo de lógica a mesma importância outrora atribuída ao estudo de línguas". $\mathrm{O}$ resultado seria a disseminação da concepção de filosofia promovida pelos analíticos:

Graças ao baby boom do pós-guerra, os anos 1960 e o início dos anos 1970 foram também o período no qual a maioria dos doutores em filosofia atualmente vivos nos Estados Unidos foram formados. O resultado é que a maioria dos professores de filosofia das instituições de ensino superior do país assimilaram alguma versão da imagem da história da filosofia. (...) Eles foram criados para verem-se a si mesmos como participantes privilegiados do começo de uma nova era filosofia - a Era da Análise, na qual as coisas finalmente seriam feitas de forma adequada. Foram, no geral, levados a desprezar o tipo de pessoa interessada na história da filosofia, ou mais genericamente na história das

TOLEDO JÚNIOR, Joaquim Elói Cirne de. Richard Rorty e a emergência da filosofia pós-analítica nos Estados Unidos: transformações institucionais e crise disciplinar, 1970-1980. Griot : Revista de Filosofia, Amargosa/Bahia, v.17, n.1, p.377-397, junho/2018. 
ideias, em vez de interessada na solução de problemas filosóficos". (RORTY $1982)^{2}$

No entanto, para além das questões a respeito da "natureza e futuro da filosofia" que para Rorty são centrais, o fato de que a filosofia analítica, naquele momento, parecia não ser capaz de cumprir suas próprias promessas era sintomático. Se nos anos 1950 um aluno típico de pós-graduação teria sido instruído a reconhecer os "verdadeiros problemas da filosofia" (como, por exemplo, o problema do "condicional contrafactual", ou de se uma análise psicológica, "emotiva" de termos éticos era satisfatória, ou o problema da natureza dos enunciados analíticos, etc.) e a aplicar métodos rigorosos em sua solução (segundo os exemplos de Russell, Frege e Tarski), nos anos 1980, em vez de um horizonte teórico claro e distinto, prevalecia uma cacofonia de paradigmas no interior da própria filosofia analítica:

O que é considerado um problema para um doutor da universidade da Califórnia não é necessariamente um problema para um doutor de Chicago ou de Cornell, e vice-versa. Um problema que esteja em voga simultaneamente em dez das centenas de departamentos de filosofia 'analítica' nos Estados Unidos pode ser considerado um enorme sucesso. O campo, hoje, é uma selva de programas de pesquisa que competem entre si, programas que parecem ter sobrevida cada vez menor.

Embora a maioria dos filósofos se identificasse àquela altura com a abordagem analítica, para Rorty não havia um "paradigma interuniversitário consensual do trabalho filosófico, tampouco uma lista consensual de "problemas centrais" (RoRTY 1982).

O problema começa, insiste Rorty, justamente com o esforço inútil de demarcar as fronteiras disciplinares da filosofia. Parte importante do sucesso da filosofia analítica foi construído em cima da noção de que era possível e necessário demarcar essas fronteiras de forma a incluir em seu interior Kant, Frege e Russell, por exemplo, e excluir Hegel, Kierkegaard e Sartre. Problemas filosóficos seriam exclusivamente aqueles que tratam da "natureza e possibilidade do conhecimento científico"; no entanto, ninguém mais sabia, ou cada departamento, ou cada filósofo, tinha uma ideia particular de quais problemas seriam esses, e a filosofia analítica nos últimos anos fora capaz de preservar apenas uma unidade estilística e por assim dizer pro forma: da mesma maneira que Quine descontruíra a noção de "axioma" sugerindo que um axioma é qualquer coisa que apareça em uma lista intitulada "Axiomas", os problemas da filosofia analítica passaram a ser aqueles "sobre os quais as pessoas importantes do campo estão falando". A transformação é bem-vinda, avalia Rorty: com esse deslocamento, a filosofia analítica - de momento culminante da "verdadeira" filosofia a mais um gênero intelectual entre outros - se aproximaria, do ponto de vista de sua autoimagem, das demais disciplinas das humanidades, sem pretensões para além de oferecer contribuições criativas ao debate cultural.

2 Todas as traduções são de minha responsabilidade, exceto quando indicado.

TOLEDO JÚNIOR, Joaquim Elói Cirne de. Richard Rorty e a emergência da filosofia pós-analítica nos Estados Unidos: transformações institucionais e crise disciplinar, 1970-1980. Griot : Revista de Filosofia, Amargosa/Bahia, v.17, n.1, p.377-397, junho/2018. 
Assim como os nossos colegas na História e na Literatura sabem, as humanidades se distinguem das ciências naturais precisamente porque não sabemos antecipadamente quais são os nossos problemas, e não precisamos oferecer critérios de identidade que nos digam se os nossos problemas são os mesmos do que os dos nossos antepassados. (RORTY 1982)

Para Rorty, a retórica de cientificidade da filosofia analítica se presta a pouco mais do que à manutenção das fronteiras disciplinares externas (distinguindo a filosofia das demais disciplinas das humanidades) e a produzir uma escala hierárquica interna entre as diferentes escolas de filosofia. Os esforços metafilosóficos de distinção entre a filosofia analítica e o "resto", insiste Rorty, são antes questões de política acadêmica do que epistemológicas.

$*$

"Philosophy in America today" é um texto de combate, e deve ser lido menos como uma análise neutra do estado da disciplina e mais como uma intervenção, em idioma histórico-filosófico, nas disputas intelectuais do dia. Dois anos antes, em 1979, Rorty assistira da cadeira de presidente o levante dos pluralistas contra os analíticos no encontro da divisão leste da Associação Americana de Filosofia, e suas decisões foram cruciais para conferir legitimidade ao movimento que demandava maior espaço nas instituições da vida filosófica profissional do país (TOLEDO 2015, capítulo 1) a filósofos não-analíticos. O final dos anos 1970 e a década de 1980 seriam prolíficos na produção de críticas à filosofia analítica e na identificação, defesa e promoção da emergência de uma filosofia "pós-analítica" no cenário profissional norte-americano. O período seria marcado, assim, por uma sensação de profunda "crise" da disciplina: se a filosofia analítica mostrava sinais de esgotamento criativo e transformara sua influência intelectual em exercício de poder institucional, o que a poderia substituir como referência para o trabalho intelectual de filósofos profissionais? Ou, ainda, seria mesmo preciso que algo específico - uma nova concepção do que é trabalho filosófico genuíno ocupasse esse lugar? Ou a filosofia profissional americana havia ingressado definitivamente em uma era "pós-Filosófica" (RORTY 1979) e pluralista?

A narrativa da hegemonia da filosofia analítica nos Estados Unidos e do "retorno do reprimido" composto pelas linhagens relegadas a segundo plano no período a partir dos anos 1970 se tornaria lugar-comum entre os observadores do rumo da disciplina nos anos 1980. John Rajchman (à época da universidade Fordham), um dos editores da importante coletânea Post-analytic philosophy (RAJCHMAN e WEST 1985) reconstruira a história da filosofia no país segundo a narrativa da decadência da filosofia "nacional" e "pública" do pragmatismo clássico e da ascensão de "programas filosóficos mais

TOLEDO JÚNIOR, Joaquim Elói Cirne de. Richard Rorty e a emergência da filosofia pós-analítica nos Estados Unidos: transformações institucionais e crise disciplinar, 1970-1980. Griot : Revista de Filosofia, Amargosa/Bahia, v.17, n.1, p.377-397, junho/2018. 
especializados" introduzidos, segundo Rajchman, pelos emigrés austríacos e alemães ligados ao positivismo lógico ${ }^{3}$ :

Sob sua influência, ao final dos anos 1950 o mainstream da filosofia norteamericana havia se tornado uma ocupação especializada com problemas formais precisos, que dispensava o debate público, desautorizava as exigências de erudição literária ou histórica, menosprezava o pensamento existencial e fenomenológico e via pouca ciência e nenhuma filosofia na psicanálise e no marxismo. A filosofia se tornou um refúgio recôndito" (RAJCHMAN e WEST 1985, p. ix).

No entanto, esse cenário que caracterizara a disciplina nos últimos 25 anos estava se transformando: "filósofos influentes emergem de suas preocupações especializadas, desafiando o caráter 'profissionalizado' da disciplina, e levantando abertamente a questão de se, nas palavras de [Hilary] Putnam, seus programas básicos não chegaram a um beco sem saída". Embora tenha produzido pelo menos duas gerações de filósofos notáveis, seus pressupostos haviam sido "minados por seu próprio trabalho técnico (...). A própria noção de análise lógica foi colocada em questão. Talvez não exista um método ou lógica da ciência, nada 'filosófico' a ser estudado. Talvez não existam sentenças analíticas, e os filósofos analíticos não tenham o que "analisar" (RAJCHMAN e WEST 1985, p. x-xi)

Filósofos analíticos de reputação estabelecida como Hilary Putnam, Arthur Danto e o próprio Rorty (que, entre outros, figuravam na coletânea como principais expoentes da emergente filosofia pós-analítica), entre outros, ofereciam explicações para os impasses da filosofia analítica e seu aparente esgotamento. Para Putnam, em artigo cujo alvo é Ayer,

As realizações da filosofia analítica são apenas negativas; ela destruiu os próprios problemas que estavam em sua origem por meio de fracassos sucessivos em até mesmo determinar que tipo de solução eles poderiam ter [...]. A filosofia analítica tem a pretensão de ser não apenas um movimento importante da história da filosofia - o que certamente foi - mas de ser a própria filosofia. Essa autodescrição força os filósofos analíticos [...] a oferecer continuamente novas 'soluções' para os problemas do empirismo - soluções que são cada vez mais bizarras, e que perderam todo seu interesse fora da comunidade filosófica. Assim, temos um paradoxo: no mesmo momento em que a filosofia analítica é reconhecida como o 'movimento dominante' da filosofia mundial, ela chega ao final de seu próprio projeto - a um beco sem saída, não à linha de chegada" (PUTNAM 1984).

3 Na verdade, a consolidação do espírito técnico e profissional na filosofia norte-americana é um desenvolvimento autóctone ligado à institucionalização da filosofia universitária e dos desenvolvimentos teóricos do pragmatismo de Harvard. Os influxos externos mais relevantes vieram não da Europa continental mas da Inglaterra, via o círculo de Russell. Os filósofos de língua alemã ligados ao empirismo lógico do Círculo de Viena teriam presença e impacto relativamente tardio e reduzido, embora retrospectivamente tenham ocupado o papel de "heróis" - ou vilões - da filosofia analítica no país (cf. COLlins 1988, KuKLiCK 2000 e TOLEDO 2015).

TOLEDO JÚNIOR, Joaquim Elói Cirne de. Richard Rorty e a emergência da filosofia pós-analítica nos Estados Unidos: transformações institucionais e crise disciplinar, 1970-1980. Griot : Revista de Filosofia, Amargosa/Bahia, v.17, n.1, p.377-397, junho/2018. 
Em 1980, Danto identificara o mesmo paradoxo entre o fracasso teórico da filosofia analítica e seu "sucesso institucional" (DANTO 1984). A história da filosofia analítica, afirma, pode ser lida como uma sequência de "reformas fracassadas" que "assumiram a forma de programas de explicação linguística que deveriam não apenas dar aos filósofos uma tarefa como também paralisar as velhas inclinações [filosóficas] ao negar-lhes lugar". No entanto, após um século de suposto expurgo da filosofia de suas fixações metafísicas, "a maioria dos médicos faleceu enquanto o paciente prospera, e em breve talvez nos daremos conta de que não sabemos o que a filosofia realmente é. O que ela é talvez seja seu problema mais urgente e, possivelmente, seu único problema". Mesmo assim, a filosofia analítica "prevalece sobre seus rivais"; é o estilo adotado "pelos filósofos consagrados nos departamentos consagrados, e por seus alunos e alunos de seus alunos em departamentos menos famosos. Seu espírito, tom e técnicas predominam não apenas nos Estados Unidos e no Reino Unido, mas em toda a civilização ocidental" (RAJChMAN e WeST 1984).

Danto sugere que a era da filosofia analítica foi também a era da "austeridade" filosófica e que essa era chegara ao fim. A análise significou, para os expoentes da tradição, eliminação: de conceitos complexos, de conceitos confusos, de áreas inteiras da filosofia cativas das ilusões da má compreensão do sentido de algumas expressões filosóficas cruciais. E, se a preocupação com a austeridade teórica chegara ao fim, "um dos principais motivos para praticar a filosofia analítica desapareceu com ela", afirma Danto. A esperança da filosofia analítica fora uma espécie de desassombramento dos mundos dos filósofos do passado (...). Mas a esperança acabou (e não apenas porque o truque não funcionou). A terapia foi abandonada. Mas uma boa parte da ideologia da análise continua em voga na retórica ameaçadora [da] confusão [e do] pseudoproblema" (RAJChMAN e WEST 1984). Ainda que mortalmente feridos na esfera teórica, os analíticos dificilmente largariam o osso da proeminência profissional.

\section{A dupla crise da filosofia analítica: esgotamento teórico e desafio à hegemonia institucional}

É possível interpretar esse conjunto de críticas explícitas à filosofia analítica de início dos anos 1980, muito semelhantes entre si, para além de um debate que se desenrola exclusivamente no plano teórico. O questionamento teórico de fronteiras disciplinares - entre filosofia e ciência, mas também entre filosofia analítica e o "resto" da tradição filosófica - corre paralelo a uma transformação crucial na estrutura do campo profissional, que nas últimas décadas passara por um novo ciclo de expansão, acompanhando as transformações do sistema de ensino superior norte-americano. Abordagens que não aquelas gestadas no interior das redes intelectuais que deram forma à filosofia profissional norte-americana entre o final do século XIX e a primeira metade do século XX não tinham cidadania filosófica naquele meio até pelo menos os primeiros anos da década de 1960; mas a hegemonia dos analíticos foi abalada em dois fronts simultâneos e diretamente relacionados: de um lado, no acúmulo de críticas internas a

TOLEDO JÚNIOR, Joaquim Elói Cirne de. Richard Rorty e a emergência da filosofia pós-analítica nos Estados Unidos: transformações institucionais e crise disciplinar, 1970-1980. Griot : Revista de Filosofia, Amargosa/Bahia, v.17, n.1, p.377-397, junho/2018. 
seus pressupostos e fracassos teóricos; de outro, no contexto de expansão e adensamento do meio de filosofia profissional que resulta da política de expansão, descentralização e diversificação do sistema de ensino superior norte-americano no pós-guerra. As novas gerações de filósofos, representados pelos integrantes da chamada Revolta Pluralista de 1979 (TOLEDo 2015), apenas terminaram o trabalho iniciado pela lenta sabotagem interna ao mainstream analítico, a partir dos anos 1960, por filósofos ainda identificados com aquela tradição.

A insatisfação com os rumos da disciplina chega a seu auge entre final dos anos 1970 e início dos anos 1980, mas suas origens devem ser buscadas algumas décadas antes. No restante deste artigo, consideraremos duas condicionantes que nos parecem cruciais para explicar a irrupção do sentimento anti-analítico no âmbito teórico e no âmbito institucional da filosofia norte-americana: em primeiro lugar, consideraremos as transformações decorrentes da "segunda revolução acadêmica" nos Estados Unidos a partir dos anos 1960, que modificaram profundamente a estrutura da vida profissional da disciplina; em segundo lugar, retraçaremos alguns aspectos da trajetória intelectual de Richard Rorty que ajudam a entender sua posição privilegiada de formulador intelectual do movimento pós-analítico. Rorty está no entroncamento de duas tradições ou, mais especificamente, de duas redes intelectuais, que podemos provisoriamente identificar como, de um lado, a metafísica de Yale e, de outro, a filosofia analítica de Harvard. Ao fazê-las convergir nos anos 1960, Rorty se posicionaria estrategicamente no principal "buraco estrutural", para usar a expressão de Ronald S. Burt (BURT 2004) da filosofia profissional norte-americana. Burt mostrou como, em organizações dos mais diversos tipos, pessoas que se conectam a círculos profissionais diversos estão em posição de maior vantagem para elaborar "boas ideias" - que, no caso das disciplinas acadêmicas, podemos usar como um correlato de inovação intelectual - do que pessoas pertencentes a apenas um circuito. A consideração da trajetória intelectual de Rorty entre os anos de formação e sucesso profissional - entre meados dos anos 1950 e a década de 1960 - ajuda a entender por que o autor de Philosophy and the mirror of nature foi protagonista no processo de emergência da filosofia pós-analítica nos Estados Unidos.

Rorty foi pioneiro na elaboração das críticas à filosofia analítica que se tornariam lugar-comum nos anos 1980. Em 1967, em introdução à coletânea The linguistic turn (Rorty [1967] 1992), Rorty enumerou o que considerava ser as "dificuldades metafilósoficas" da "filosofia linguística". A "revolução da filosofia linguística" - "a concepção de que problemas filosóficos são problemas que podem ser resolvidos (ou dissolvidos) ou por meio de uma reforma da linguagem ou pelo aprofundamento da nossa compreensão do funcionamento da linguagem que utilizamos" - fora celebrada como "a mais importante descoberta filosófica" do século XX, mas dava sinais de não ser capaz de corresponder às suas principais promessas neutralidade axiológica, clareza metodológica e consenso teórico. Começar pelo critério de sentido das expressões linguísticas (incluindo as filosóficas) e só admitir no discurso filosófico as que passassem pelo teste parecia fornecer à filosofia linguística um ponto de partida livre de pressupostos filosóficos substantivos. A. J. Ayer, por exemplo, atacava a metafísica de Francis H. Bradley não pela acusação clássica de que ela "tentava

TOLEDO JÚNIOR, Joaquim Elói Cirne de. Richard Rorty e a emergência da filosofia pós-analítica nos Estados Unidos: transformações institucionais e crise disciplinar, 1970-1980. Griot : Revista de Filosofia, Amargosa/Bahia, v.17, n.1, p.377-397, junho/2018. 
aplicar o entendimento em um campo onde não podia se aventurar", mas porque resultava em "sentenças que não se conformavam às únicas condições sob as quais uma sentença pode literalmente ter sentido". As proposições da filosofia, afirmava Ayer, "não são factuais, mas linguísticas - ou seja, não descrevem o comportamento de objetos físicos, tampouco mentais; expressam definições, ou as consequências formais, de definições. Podemos dizer, assim, que a filosofia é um departamento da lógica". Rudolf Carnap também havia submetido a metafísica de Heidegger à mesma crítica: as formulações deste revelavam, segundo Carnap, uma falta de compreensão da "sintaxe lógica da linguagem", e tanto Ayer quanto Carnap pareciam concordar que a análise linguística - via verificação ou confirmação, isto é, pela determinação dos procedimentos que a verificariam ou confirmariam - podia mostrar que algumas sentenças possuíam sentido e outras não, e, consequentemente, podia separar problemas e discursos filosóficos (e também científicos) legítimos dos ilegítimos. Mas os critérios de verificação ou confirmação eles próprios não evitam uma circularidade:

\begin{abstract}
Como ficou claro para Carnap e Ayer [...], não existe lógica filosoficamente neutra que autoriza juízos pejorativos a respeito de teses filosóficas [...]. A "lógica" de Language, truth and logic (Ayer) e de The logical syntax of language (Carnap) estava longe de não ter pressupostos. Apenas parecia que não tinha pressupostos para quem estivesse previamente convencido dos resultados de sua aplicação, e estivesse, portanto, disposto a aceitar definições filosoficamente carregadas de termos como "lógica", "sentido" e similares. (Rorty [1967] 1992: 6).
\end{abstract}

Se o que Rorty (1967) chama de "filosofia linguística" - um termo que recobre, no geral, a mesma tradição designada pela noção mais geral de "filosofia analítica" não pode alegar um ponto de partida neutro para seus critérios de sentido (isto é, se as próprias noções de "análise" e "lógica" são filosoficamente carregadas), ela tampouco exibe a clareza metodológica que supostamente a caracterizaria. O próprio campo da filosofia da linguagem se dividiu entre filosofia da linguagem ideal e filosofia da linguagem ordinária, embora, do ponto de vista do entendimento metateórico, a controvérsia não teria lugar: os objetivos são os mesmos - limpar o terreno filosófico dos entulhos da tradição - e não haveria diferença entre "oferecer uma alternativa à linguagem ordinária ou denunciar seu uso indevido". A tensão entre filosofia da linguagem ideal e da linguagem ordinária revela, por sua vez, o problema do que Rorty chama de "critérios de sucesso" da análise: se não há consenso em torno do método a empregar, não há critérios compartilhados que permitam afirmar, acima de qualquer dúvida, que um acordo racional na solução de problemas filosóficos foi atingido ou sequer seja possível. "A quantidade de acordo entre filósofos da linguagem a respeito dos critérios de sucesso filosófico é inversamente proporcional à relevância dos seus resultados para problemas filosóficos tradicionais", escreve (RORTY 1967).

Rorty foi o primeiro a apontar para as inconsistências do programa analítico, e suas críticas, àquela altura, são menos as de um outsider do que a de um aliado heterodoxo. Acima de tudo, suas críticas são, para usar uma expressão que lhe é cara no

TOLEDO JÚNIOR, Joaquim Elói Cirne de. Richard Rorty e a emergência da filosofia pós-analítica nos Estados Unidos: transformações institucionais e crise disciplinar, 1970-1980. Griot : Revista de Filosofia, Amargosa/Bahia, v.17, n.1, p.377-397, junho/2018. 
artigo de 1967, "metafilosóficas". A filosofia analítica - ou filosofia linguística - teria se desenvolvido não apenas a partir de uma ideia da filosofia enquanto ciência, mas também sob uma concepção "espectatorial" do conhecimento. Para Rorty, os problemas tradicionais da epistemologia e da metafísica que continuavam a assombrar os filósofos, mesmo aqueles que procuravam virar as costas para o passado da disciplina em favor de um admirável mundo novo da filosofia analítica, tinham origem em uma mesma concepção do conhecimento como a apresentação de algo "dado" à mente, esse "olho imaterial", sem mediação linguística. Para Rorty a tensão entre filosofia analítica e a tradição só seria superada em uma instância superior: no abandono da imagem moderna do conhecimento e na substituição da ideia de filosofia enquanto "descoberta" pela ideia da filosofia enquanto "criação". Com esse prognóstico, Rorty elaborava as bases para os argumentos que desenvolveria na próxima década e que seriam o ponto de partida de sua obra central, Philosophy and the mirror of nature, publicado em 1979.

\section{As transformações do ensino superior norte-americano no pós-guerra}

Se erguermos os olhos da penumbra da elaboração teórica para o horizonte mais amplo da vida intelectual profissional, no entanto, vemos que essas queixas em relação à filosofia analítica são parte de um padrão de transformações institucionais que dão impulso a uma mudança de atitude em relação ao trabalho intelectual e às práticas do meio profissional no meio filosófico norte-americano. Desde os anos 1960 o sistema universitário se expandiu e diversificou, e as universidades tradicionais viram sua eminência questionada pela primeira vez por novas instituições privadas e, principalmente, pelas novas instituições criadas com a injeção de dinheiro público resultante da modificação da política pública para o setor no contexto da Guerra Fria resultando, nos anos 1970, em uma crise representada pelo inchaço do próprio sistema que se refletiria, principalmente nas humanidades, em uma crise disciplinar. É um exagero dizer que a centralidade do chamado "modelo de Harvard" - a contratação e promoção do corpo docente em função de credenciais educacionais, a começar pelo $\mathrm{Ph}$. D., e em função de produtividade medida pela frequência, volume e impacto de publicação - tenha sido abalada e, mesmo na filosofia, Harvard permaneceu no topo da estrutura de prestígio, que pouco se alterou nas décadas seguintes - é possível até mesmo que o "modelo de Harvard" tenha se consolidado apesar da crise teórica e institucional na filosofia.

No entanto, as evidências - a revolta pluralista, as queixas contra o programa analítico e a emergência de uma geração de filósofos identificados com a ideia de uma filosofia "pós-analítica" - apontam para uma profunda transformação em curso. De um pequeno circuito centrado em poucos departamentos e uma associação profissional com 120 membros nos anos 1920, a filosofia se transformaria, a partir da expansão do sistema de ensino superior nos anos 1950-60, em uma disciplina cuja escala espelhava a nova realidade da comunidade científica da segunda metade do século XX: uma explosão demográfica que faria a população de filósofos profissionais saltar para mais de 8 mil membros nos anos 1990, formados pelos mais de noventa departamentos que

TOLEDO JÚNIOR, Joaquim Elói Cirne de. Richard Rorty e a emergência da filosofia pós-analítica nos Estados Unidos: transformações institucionais e crise disciplinar, 1970-1980. Griot : Revista de Filosofia, Amargosa/Bahia, v.17, n.1, p.377-397, junho/2018. 
passaram a emitir títulos de Ph. D. (KuKLICK 2000: 259-260). O amplo influxo de recursos no sistema também elevaria a qualidade geral dos cursos de pós-graduação, e instituições, novas e antigas, das mais diferentes orientações teóricas - inclusive religiosas como Notre Dame, Fordham e Loyola - passariam a ocupar lugar de destaque nos rankings elaborados anualmente pela Associação Americana de Filosofia ${ }^{4}$, e novos centros dedicados à continuação do programa analítico - como MIT, a Universidade da California em Irvine e a NYU - desafiariam a hegemonia da linhagem de Harvard. A filosofia analítica de Harvard teria de combater em um front externo contra um novo inimigo emergente e um front interno contra aliados ambiciosos.

Se as duas primeiras décadas do pós-guerra foram consideradas os anos da "revolução universitária" norte-americana (JENKS e RIESMAN 1968; GRAHAM e DIAMOND 1997), os anos 1970 e 1980 são inequivocamente de crise. A interrupção brusca, ainda que prevista, da expansão do sistema de ensino superior, a queda na procura por cursos de graduação e de pós-graduação em humanidade, que prepara para carreiras acadêmicas, assim como a queda na participação desses cursos no total das credencias emitidas (em especial no nível mais alto, o $\mathrm{Ph}$. D.) e a maior procura por cursos "vocacionais" ou profissionalizantes indicam uma crise ainda mais aguda no meio das humanidades. Essa crise foi sentida, em leitura conservadora, como crise cultural e decadência de valores humanistas tradicionais ligados à missão do ensino superior (BLOOM 1987), ambas consequências das "guerras culturais" dos anos 1960 e 1970, ou, em leitura menos ideologicamente carregada, como "desidentificação" e perda de influência das disciplinas que compunham o campo algo vago das humanidades entre a nova geração de estudantes, resultado da queda de prestígio dos cursos de humanidades para a formação científica e da perda de ênfase no mérito acadêmico em favor de uma relação de consumo com o ensino superior, tanto por gestores quanto por estudantes (RIESMAN 1980). As humanidades teriam falhado em se adaptar a um mundo país que passava por profunda mudanças demográficas e culturais (BELL 1966).

Acima de tudo, porém, trata-se de uma crise estrutural concreta - institucional, para ser mais exato -, e não apenas de identidade disciplinar ou teórica. Até meados do século XIX, o incipiente sistema de ensino superior americano empregava poucos professores e atraía pequeno número de alunos. Entre o final do século XIX e início do século XX, os pesquisadores norte-americanos haviam se organizado em disciplinas e associações profissionais, fundado publicações especializadas e criado programas de doutorado para formar novos professores (JENKS e RIESMAN 1968; KUKLICK 1979; Campbell 2006; Toledo 2015). O mesmo ocorreu com as humanidades (incluindo a filosofia), que encontraram nos departamentos universitários seu local principal de produção (KUKLICK 1979 e 2000; CAMPBELL 2006): o estudo sistemático das disciplinas geralmente agrupadas sob o conjunto "humanidades" - estudos literários, história, filosofia, artes - passou a se concentrar em instituições de ensino superior, também maiores responsáveis pelos empregos e carreiras de profissionais da área. No auge de sua expansão, isso significou, segundo Roger L. Geiger, que o sistema de ensino superior

${ }^{4}$ Desde 2003 a APA não elabora mais o ranking. http://www.apaonline.org/?rankings

TOLEDO JÚNIOR, Joaquim Elói Cirne de. Richard Rorty e a emergência da filosofia pós-analítica nos Estados Unidos: transformações institucionais e crise disciplinar, 1970-1980. Griot : Revista de Filosofia, Amargosa/Bahia, v.17, n.1, p.377-397, junho/2018. 
norte-americano ofereceu "emprego para o maior conjunto de humanistas profissionais do mundo", cujo trabalho garantiu a exposição a temas das humanidades para o que era também "a maior população mundial de estudantes pós-secundaristas" (GEIGER 2006: $50)$.

As transformações demográficas nas universidades, e em especial nas humanidades, nos Estados Unidos entre as décadas de 1950 e 1980 afetaram o trabalho intelectual nas correspondentes disciplinas. Essas mudanças nas estruturas da vida intelectual profissional estão relacionadas a transformações tanto no plano da concepção geral do papel das humanidades no currículo do ensino superior quanto no plano da natureza mais específica do trabalho intelectual nas diferentes disciplinas.

Os anos 1950 nos Estados Unidos assistem a um primeiro impulso de massificação do ensino superior resultante de programas de bolsa de estudos para soldados retornados da guerra, a chamada G.I. Bill. Nesse processo, as humanidades compartilharam com as demais ciências e com cursos de perfil mais vocacional ou profissionalizante o crescimento vertiginoso do número de estudantes viabilizado pelo aumento exponencial do gasto público com educação superior por meio daquele programa e também graças às novas políticas para o setor determinadas pelas preocupações da Guerra Fria (HoLlinger 2006). O sistema de ensino norte-americano já se encontrava em meio a um processo de expansão, com o aumento da população de estudantes secundaristas. $O$ aumento no número de alunos matriculados em cursos de graduação colocou, por circunstâncias diversas, os humanistas à frente do processo de redefinição dos currículos básicos dos cursos universitários, agora supostamente voltados não mais a uma pequena elite de estudantes, mas a uma grande parcela de um extrato social que, no geral, frequentava pela primeira vez cursos superiores ${ }^{5}$ Essa expansão reflete uma transformação demográfica: entre 1950 e 1970: o número de adolescentes (17 anos) duplicou, e a frequência no ensino secundário passou de $60 \%$ a $75 \%$ dessa população; ao mesmo tempo, a chance de um aluno egresso do ensino secundário ingressar em um curso superior aumentou de $42 \%$ para $53 \%$, resultando em "um aumento de quase três vezes de estudantes ingressantes no primeiro ciclo do ensino superior [college]" (GEIGER 2006: 50). No período, o total de matrículas em cursos de graduação passou de 2 milhões a/a para 9 milhões, em uma expansão sem precedentes, provavelmente, em toda a história e em todo o mundo.

No entanto, em meados dos anos 1970 esse ritmo de crescimento é interrompido, e o ensino superior norte-americano para de crescer pela primeira vez em sua história (GEIGER 2006). O impacto dessa brusca interrupção é sentido de maneira mais aguda no meio das humanidades. No final do ciclo dos estudantes ingressantes graças à G.I. Bill nos primeiros anos da década de 1950, disciplinas como línguas e história respondiam por cerca de $8 \%$ do total de diplomas secundários; ao longo dos anos 1950 esse número aumentou para $10 \%$, chegando a $16 \%$ em meados de 1960 , período no qual o total absoluto de formados em cursos de humanidades triplicou. Mas nos anos 1970 esses

\footnotetext{
${ }^{5}$ Em 1965 é criado o National Endowment for the Humanities, que "consolidou o lugar dos humanistas na Revolução Acadêmica" norte-americana. Cf. HoLLINGER 2006.
}

TOLEDO JÚNIOR, Joaquim Elói Cirne de. Richard Rorty e a emergência da filosofia pós-analítica nos Estados Unidos: transformações institucionais e crise disciplinar, 1970-1980. Griot : Revista de Filosofia, Amargosa/Bahia, v.17, n.1, p.377-397, junho/2018. 
números despencam, e por volta de 1985 as humanidades respondiam por menos de $6 \%$ do total de diplomas de graduação. O mesmo padrão é observado para diplomas de doutorado: a queda na demanda por cursos de humanidades se reflete num arrocho do mercado de trabalho no ensino superior, inundado por um excedente de profissionais qualificados em disciplinas que, ao que tudo indicava, haviam perdido seu prestígio.

Para Geiger, essa crise estrutural (de baixa procura e saturação, acompanhada por estagnação, do mercado de trabalho) é acompanhada por uma crise referente a seu lugar no currículo do ensino superior:

\begin{abstract}
Nas discussões estratégicas a respeito do perfil da educação superior no pósguerra, as humanidades foram colocadas em lugar de honra como componentes fundamentais de uma educação liberal. Elas claramente se valeram desse destaque nos anos de rápida expansão. No auge de sua popularidade, no entanto, as humanidades foram atingidas por controvérsias em torno de sua relevância e acusações de viés político. (GEIGER 2006: 51)
\end{abstract}

Vale retraçar brevemente esse processo de expansão e estagnação ("boom and burst", para usar a formulação de Geiger) entre os anos 1950 e 1980 e suas prováveis causas, ligadas a transformações diversas como aumento da procura por cursos vocacionais (associados à perda de prestígio e centralidade das humanidades nas orientações curriculares gerais do ensino superior), à mudança no perfil dos estudantes (aumento da participação de mulheres e minorias) e a mudanças de orientação teórica nas próprias disciplinas.

\title{
As humanidades no novo ensino superior: ascensão e crise
}

As humanidades foram convocadas no pós-guerra a desempenhar papel central no sistema de educação norte-americano, oferecendo o fundamento ao que foi chamado na época de "educação geral", conceito introduzido e desenvolvido no influente relatório de 1945 elaborado por Harvard, General education in a free society [Educação Básica em uma sociedade livre], na gestão de James B. Conant. O relatório tinha como preocupação não apenas o circuito de elite de Harvard, mas todo o sistema educacional do país, e defendia os objetivos de promover uma "cidadania democrática" e a "utilidade social" da educação. O relatório articulava uma insatisfação com o currículo e práticas do ensino superior no período anterior à guerra, e seus princípios gerais foram incorporados pela Comissão para a Educação Superior da gestão Harry Truman, criada em 1947. Esses e outros documentos de política educacional indicam o papel central e estratégico das humanidades no currículo do sistema de educação (básico e superior) no seu período de rápida expansão e transformação no pós-guerra. Para Jenks e Riesman (1968), um dos efeitos essenciais da "revolução acadêmica" norte-americana foi a forte influência que os programas de pós-graduação em humanidades e ciências passaram a desempenhar sobre o currículo dos cursos de graduação, assim como a posição de destaque que o corpo docente dessas áreas assumiu sobre a vida educacional geral do país:

TOLEDO JÚNIOR, Joaquim Elói Cirne de. Richard Rorty e a emergência da filosofia pós-analítica nos Estados Unidos: transformações institucionais e crise disciplinar, 1970-1980. Griot : Revista de Filosofia, Amargosa/Bahia, v.17, n.1, p.377-397, junho/2018. 
As escolas de pós-graduação são a principal força de expansão da universidade moderna [...]. Seu status também tem se elevado, e ocupam uma posição comparável àquela da teologia na universidade medieval. Os departamentos de pós-graduação são em sua maioria autotélicos. Ressentem-se até mesmo de serem questionados a respeito de se geram benefícios para a sociedade para além da edificação de seus próprios membros, e taxam de anti-intelectuais os que colocam esse tipo de questão". (JENKS e RIESMAN 1968: 57)

A expansão significou, ao mesmo tempo, tanto um aumento em termos absolutos e relativos de estudantes em todos os níveis (os Estados Unidos seriam o primeiro país do mundo a criar um sistema de massa de educação secundária) quanto a expansão do sistema em si, com a criação de novas instituições de ensino superior em todo o território nacional. Essa expansão limitou o peso de instituições tradicionais no sistema de ensino superior e criou, ao lado de novas instituições de excelência que competiam com as mais antigas (Harvard, Yale, Chicago etc), outras menores, de segundo e terceiro escalão, cruciais para a reconfiguração do perfil de estudantes e do mercado de trabalho para pós-graduados que buscavam uma carreira nas humanidades.

Os anos 1960, em termos demográficos, viveram uma expansão importante. Na década anterior, embora o ingresso de ex-combatentes via a referida G.I. Bill tenha sido crucial para restabelecer o patamar normal do perfil demográfico do ensino superior (que havia sentido, naturalmente, o esvaziamento resultante dos esforços de guerra e da ausência de homens, e também mulheres, da faixa etária pertinente), pouco havia mudado: o número de estudantes que ingressaram via G.I. Bill chegou a seu pico em 1949-1950, e, como dissemos, não mais que 6\% concluíram cursos de humanidades, provavelmente o mínimo histórico total (GEIGER 2006: 54), oscilando na década de 1950 a um máximo de 8\%. ${ }^{6} \mathrm{Na}$ primeira metade dos anos 1960, o total de formados em humanidades cresceu de $8 \%$ para $12 \%$ para homens, um aumento de $50 \%$, e de $15 \%$ para $21 \%$ para mulheres.

Essa transformação é anterior aos efeitos no ensino superior da explosão demográfica conhecida como baby boom, que atingiria a universidade nos anos 1960. A opção pela formação em humanidades, tanto em graduação como pós-graduação (agora a trilha obrigatória para uma vida profissional nas universidades), viveria seu pico no período, mas nos anos subsequentes, marcadamente a partir de 1975, sofreria uma queda brusca, atingindo seu ponto mais baixo no começo da década de 1980. Não é à toa que a "crise profissional" pela qual passa a filosofia (assumindo as formas diversas da crise de identidade e relevância, crise teórica e de insatisfação disciplinar) coincide com esse mesmo período. Podemos falar, assim, com Geiger (2006), em dois momentos relevantes para as humanidades no período entre 1950 e 1980: o boom, do início da

${ }^{6}$ Entre as mulheres, as humanidades contariam 15\% do total de diplomas obtidos. Língua e literatura eram disciplinas predominantemente femininas; história e filosofia, predominantemente masculinas (em proporção de 2 para 1, aproximadamente). A década é marcada por uma participação feminina nessas disciplinas inferior até mesmo ao período pré-guerra.

TOLEDO JÚNIOR, Joaquim Elói Cirne de. Richard Rorty e a emergência da filosofia pós-analítica nos Estados Unidos: transformações institucionais e crise disciplinar, 1970-1980. Griot : Revista de Filosofia, Amargosa/Bahia, v.17, n.1, p.377-397, junho/2018. 
década de 1960 até meados da década de 1970, e o burst de meados da década de 1970 até meados da década de 1985.

Essas transformações do sistema de ensino norte-americano formam o pano de fundo institucional para a crise mais geral das humanidades que se manifestaria, no caso da filosofia, em uma série de batalhas intelectuais que ocupariam a comunidade filosófica norte-americana nos anos 1960 e 1970. Além das tensões internas à própria filosofia analítica, outros fronts seriam importantes: os antigos inimigos da filosofia analítica encastelados em instituições tradicionais como Yale, que a partir das alturas rarefeitas da metafísica haviam atacado as insuficiências da filosofia científica desde pelo menos os anos 1940, agora aliados com os expoentes do que passaria a ser chamado de "filosofia continental", que emergira a partir da recepção da fenomenologia e principalmente do existencialismo no pós-guerra e encontrara em Yale um porto seguro; os movimentos que dariam origem aos "estudos culturais", de onde emergiam pensadores feministas, afro-americanos e marxistas que trariam o debate sobre questões de gênero, raça e classe para o interior dos departamentos de filosofia, amplamente apoiados pela massa de jovens estudantes de graduação envolvidos com as guerras culturais em torno dos direitos civis, da contracultura e da oposição à guerra do Vietnã; por fim, o renascimento do interesse pela tradição da filosofia clássica americana, em especial pelo pragmatismo, mas também pelos intelectuais independentes do transcendentalismo americano pré-guerra civil como Emerson, mais "interessada pelo mundo para além da academia" do que a filosofia analítica. "Professores que privilegiavam o cânone americano", escreve Bruce Kuklick, "acreditavam que a filosofia analítica havia traído a tradição da qual se originara", e também se filiaram às hostes anti-analíticas. $O$ conjunto dessas novas (ou renovadas) tendências - metafísica, filosofia continental, estudos culturais, neopragmatismo - forma o que passou a ser chamado de "pluralismo" na filosofia norte-americana a partir dos anos 1970. A filosofia analítica lograra a proeza de reunir todo o "resto" da filosofia profissional norteamericana contra si. A balança pendia para o outro lado.

\section{Os anos 1980: crise e mudança de estilo na filosofia}

Os anos 1980 são, no geral, e não apenas nos Estados Unidos, um período de intensa redefinição das fronteiras internas da filosofia e de realinhamento das diferentes facções que compuseram a paisagem filosófica da primeira metade do século XX. As alianças e rivalidades se redesenharam, e as possibilidades de crítica e construção no interior da disciplina tomaram um novo rumo: nos Estados Unidos, a filosofia analítica e a "escola positivista" perderam, como vimos, sua hegemonia; na França, o pósmodernismo mais próprio dos intelectuais pertencentes ao circuito do mercado editorial se voltou em bloco contra as "grandes narrativas" da modernidade e suas derivações (LYOTARD 1979) e, no meio acadêmico, o pós-estruturalismo das gerações pós-1968 sinalizava uma troca geracional e um levante da periferia do sistema universitário contra o mandarinato estruturalista encastelado no seu centro (BOURDIEU 1990); na Alemanha, Jürgen Habermas e Karl-Otto Apel ignoravam as (de resto sempre fluidas)

TOLEDO JÚNIOR, Joaquim Elói Cirne de. Richard Rorty e a emergência da filosofia pós-analítica nos Estados Unidos: transformações institucionais e crise disciplinar, 1970-1980. Griot : Revista de Filosofia, Amargosa/Bahia, v.17, n.1, p.377-397, junho/2018. 
fronteiras entre a tradição anglófona e a tradição continental e combinavam Kant, Hegel e Marx com Pierce, Mead, Austin e o neopragmatismo norte-americano (Habermas [1981] 1985; APEL [1973] 1988).

Essas movimentações no campo da filosofia no período revelam a dinâmica mais geral de processos de criatividade e mudança intelectual, resultado da combinação entre as manobras no interior das redes filosóficas profissionais à medida em que "intelectuais perfazem suas carreiras através de gerações no campo intelectual" e o contexto externo dado por "movimentos sociais e políticos na vida social mais ampla que influenciam o mundo intelectual". (CoLlins 1988) A esses elementos internos e externos que influenciam os rumos da produção intelectual, devemos acrescentar um nível intermediário determinado pelas dinâmicas de estagnação, expansão ou retração das instituições da vida intelectual - neste caso, o processo de consolidação, expansão e crise do sistema de ensino superior entre o final do século XIX e o pós-Segunda Guerra nos Estados Unidos. Estudos como o de Bourdieu (1990) sugerem que esse é um padrão comum: a expansão do sistema de ensino superior francês na segunda metade do século XX promoveu um contingente de jovens professores de instituições secundárias do sistema que se sentiam "liberados dos valores tradicionais da corporação" e esteve no centro do movimento de questionamento da herança intelectual das gerações anteriores e da ascensão do "pós-estruturalismo" (Bourdieu 1990: 135). Em certa medida, podemos dizer que os anos 1980 refletem os efeitos da reação, nos anos 1960, aos estilos intelectuais predominantes nas universidades ocidentais até a década de 1950.

"A [Segunda] guerra", escreve Carl Schorske (1997: 296) em artigo sobre a emergência do "novo rigorismo" nas ciências humanas e humanidades nos anos 1950 nos Estados Unidos, "e a expansão da demanda por pesquisa puramente operacional e aplicada a serviço de objetivos políticos relativamente incontestados aprofundou o imperativo de confiabilidade científica". Economia, estudos literários, filosofia e ciências humanas seriam todas afetadas pelo mesmo processo que transformou essas disciplinas e áreas de pesquisa, antes campos "livres, pluralistas" e "ecléticos", sem "uma noção clara de missão ou método", nas quais conviviam "perspectivas críticas variadas", em "disciplinas analíticas rigorosamente focadas dotadas de forte consenso metodológico (para não dizer ortodoxas) centradas na elaboração de modelos e na verificação estatístico-empírica de hipóteses". A partir do pós-guerra, assim, emerge no meio acadêmico norte-americano um novo consenso cientificista. "A busca intelectual por objetividade científica e as vantagens profissionais da neutralidade livre de valores reforçaram-se mutuamente na consolidação de um novo consenso metodológico na base das disciplinas. Isso por sua vez afetou o perfil da formação de pós-graduandos". A filosofia compartilhou dessa guinada na direção da redefinição de seus fundamentos teóricos e de sua unificação bem-sucedida enquanto disciplina. "Confiabilidade epistemológica se tornou uma preocupação central da filosofia", escreve Schorske (1997: 299). A ciência serviria como modelo para a redefinição da "missão e métodos" desse campo de investigação. O clima local ofereceria um leque de "afinidades eletivas" com as orientações anti-metafísicas e anti-idealistas dos positivistas lógicos vindos da Europa no período que, eles próprios formados no ambiente caracterizado pelos interesses

TOLEDO JÚNIOR, Joaquim Elói Cirne de. Richard Rorty e a emergência da filosofia pós-analítica nos Estados Unidos: transformações institucionais e crise disciplinar, 1970-1980. Griot : Revista de Filosofia, Amargosa/Bahia, v.17, n.1, p.377-397, junho/2018. 
filosóficos de cientistas e matemáticos, seriam importantes para o projeto dos filósofos norte-americanos de "encontrar um locus standi autônomo em meio às forças valorativa e ideologicamente carregadas que haviam caracterizado seu campo". Na proeminência da filosofia científica em meados do século XX nos Estados Unidos vemos a convergência, portanto, de dois processos: as pressões políticas e demográficas intensificadas no contexto da Segunda Guerra e da Guerra Fria e os desdobramentos internos da tradição empirista norte-americana, incluindo influxos externos a partir dos anos 1940 .

Do ponto de vista do clima político, os anos 1960 seriam um choque para as identidades profissionais eminentemente "analíticas" de economistas, teóricos da literatura, filósofos e cientistas sociais formadas naquele período. Novos temas, politicamente carregados - a natureza do poder nas sociedades modernas, as perversões da burocracia, as diversas formas da desigualdade -, seriam dotados de urgência e relevância e passariam à ordem do dia. $\mathrm{O}$ afastamento da filosofia dos "problemas da cultura" havia sido o mais intenso entre as humanidades. "A filosofia analítica havia se tornado incapaz de responder aos desafios culturais dos anos 1960", escreve Schorske (1997: 307) - sua preocupação com problemas "conceituais e epistemológicos" a havia "conduzido a abandonar a posição sinóptica que mantinha, baseada no pragmatismo de John Dewey, em favor de um lugar ao lado das ciências extadas no extremo oposto do espectro das disciplinas".

O movimento estudantil, a contracultura, as lutas por direitos civis e a oposição à guerra do Vietnã seriam as novas forças externas pressionando por transformações nas ciências humanas e humanidades a partir dos anos 1960 nos Estados Unidos, da mesma forma que ideologias educacionais humanistas e o militarismo cientificista haviam sido, respectivamente, no final do século XIX e em meados do século XX. "Eram tempos de rebelião em um amplo front, e não surpreende que seu equivalente intelectual fosse uma rejeição veemente dos dogmas intelectuais dos mais velhos, incluindo as ciências e a filosofia analítica/positivista", escreve Collins (1988: 677). O que não é evidente, no entanto, é o mecanismo pelo qual essas forças externas afetam as redes internas do mundo intelectual profissional, normalmente voltadas para si mesmas em termos da agenda de problemas relevantes e de progressão de carreiras. A dinâmica das comunidades acadêmicas é determinada acima de tudo pela maneira como as diferentes gerações intelectuais elaboram e reelaboram o capital intelectual acumulado herdado (Collins 1998), e apenas indiretamente, ou em contextos excepcionais, pelos processos políticos e culturais do ambiente social circundante: o isolamento das redes profissionais em relação ao mundo externo é ainda mais pronunciado em disciplinas altamente abstratas e reflexivas como filosofia e matemática.

Os anos 1960, no entanto, viram a convergência dessas forças externas e as forças intermediárias ligadas às transformações estruturais do sistema de ensino superior que examinamos acima - expansão, massificação e inflação de credenciais acadêmicas, que afetaram de forma especial o meio das humanidades. Em grande medida, o que chamamos de "os anos 1960" foram mobilizações estudantis impulsionadas pelas classes médias urbanas altamente escolarizadas, e boa parte de sua pauta estava ligada a

TOLEDO JÚNIOR, Joaquim Elói Cirne de. Richard Rorty e a emergência da filosofia pós-analítica nos Estados Unidos: transformações institucionais e crise disciplinar, 1970-1980. Griot : Revista de Filosofia, Amargosa/Bahia, v.17, n.1, p.377-397, junho/2018. 
ataques ao tradicionalismo e às estruturas de poder no interior das instituições de ensino superior; naturalmente, esses ataques repercutiriam no próprio conteúdo das diferentes disciplinas. A reação comum era a resistência por parte da "velha guarda" dos professores titulares a essa intromissão do clima cultural e político geral, mas a simpatia por parte dos escalões intermediários (em especial estudantes de pós-graduação) (Collins 1988; Bourdieu 1990). Reflexos do clima de mobilização política e contracultura na filosofia norte-americana seriam evidentes em algumas obras importantes do começo dos anos 1970, como a tentativa de John Rawls de elaborar uma teoria da justiça a partir do idioma da filosofia analítica (RAWLS 1971) e o anarquismo cognitivo de Robert Nozick e Paul Feyerabend, cujo Against Method seria publicado pela editora da Nova Esquerda inglesa (NozICK 1974; FEYERABEND 1975). No final dos anos 1970, Richard Rorty sistematizaria e tornaria populares as novas orientações antipositivistas em uma releitura crítica, de cunho relativista e historicista, da emergência da "epistemologia" moderna e sua identificação espúria com toda a "Filosofia" na tradição anglo-americana (RORTY 1979).

Uma das mudanças evidentes no período, além da guinada na direção de alguns temas antes ignorados pelo mainstream filosófico, é uma mudança de estilo em sentido amplo (CoLlins 1988). Técnico e formalista, o estilo analítico revelava a ênfase na incorporação do idioma da lógica simbólica. Já a nova geração optará por um estilo mais livre, fluido e provocativo - não por acaso reminiscente dos truques literários dos ensaístas franceses que começavam a atrair a atenção dos intelectuais tanto na filosofia quanto nos estudos literários e nas ciências sociais (CuSSET 2008; LAMONT 1987). A relativa liberdade em relação à norma culta acadêmica dos franceses mais associados ao mercado editorial do que à universidade ecoaria na geração de norte-americanos que procurava uma saída para a aridez do ambiente intelectual analítico.

Mas a associação dessas mudanças de conteúdo e estilo na filosofia profissional norte-americana à emergência da contracultura dos anos 1960 peca por uma questão de timing: mudanças intelectuais demoram para ocorrer, são gestadas em silêncio, longe dos holofotes do espaço de atenção intelectual e emergem apenas quando amadurecidas. Embora, como escreve Collins (1988: 680), o pano de fundo dos anos 1960 possa ter contribuído com "energias deslegitimadoras e relegitimadoras que podiam ser canalizadas para o inevitável conflito de gerações à medida em que uma nova safra de intelectuais batalhava para deixar sua marca no terreno intelectual de seus antecessores", devemos procurar na trajetória anterior de figuras centrais desse redirecionamento da filosofia norte-americana para sua fase, conforme a chamamos, "pós-analítica", os verdadeiros deslocamentos e realinhamentos intelectuais que paulatinamente deram forma a essa mudança e culminariam na oposição mais amadurecida ao establishment analítico nos anos 1970, oposição tanto institucional quanto intelectual.

O trabalho dessa geração pioneira que emerge definitivamente nos anos 1970, da qual Rorty faz parte, é, acima de tudo, eclético e preserva, como seria de se esperar, características do "velho" estilo analítico e muitas de suas preocupações teóricas. Suas inovações são resultado do processo recorrente de criatividade intelectual caracterizado

TOLEDO JÚNIOR, Joaquim Elói Cirne de. Richard Rorty e a emergência da filosofia pós-analítica nos Estados Unidos: transformações institucionais e crise disciplinar, 1970-1980. Griot : Revista de Filosofia, Amargosa/Bahia, v.17, n.1, p.377-397, junho/2018. 
pela recombinação do capital cultural herdado de forma a "desafiar e estender o discurso normal, enquanto permanece ainda vinculado ao núcleo que garante ao intelectual individual o máximo de foco de atenção de uma audiência profissional" (COLLINS 1988: 681). Assim, a reorganização do campo intelectual filosófico a partir dos anos 1970, para além das divergências internas no campo analítico que mobilizaram o debate filosófico e resultaram em desenvolvimentos em múltiplas direções sob os pressupostos gerais das redes filosófico-matemático-científicas desde a virada do século $\mathrm{XX}$, opõe duas formas distintas de fazer filosofia, dois estilos filosóficos contrastantes o que, por sua vez, pressupõe a emergência de novos circuitos ou comunidades intelectuais onde antes prevalecia apenas uma. Ideias, assim como estilos, são propriedades de grupos - a história e a sociologia da religião têm lições importantes a dar nesse quesito. Ao mesmo tempo, a emergência dessas novas comunidades pressupõe uma reorganização, ou nova partição, do espaço de atenção intelectual. Mas processos de inovação intelectual são paulatinos, raramente disruptivos, e mais raramente ainda protagonizados por outsiders, no geral condenados ao ostracismo e ao estigma da pseudociência. $O$ processo tardio de conversão de Rorty ao estilo analítico o colocaria na posição privilegiada que Burt (2004) chamou de "buraco estrutural": com credenciais simultaneamente não-analíticas e analíticas, herdeiro por um lado da linhagem mais tradicional da filosofia das universidade de Chicago e Yale e, por força das pressões das estruturas de oportunidade profissional, emulador tardio do estilo analítico, Rorty estaria na posição de dar continuidade à crítica interna da filosofia iniciada por Quine e Sellars e, ao mesmo tempo, apontar suas insuficiências vis-a-vis outras tradições filosóficas. O lento esforço de conciliar ambas as linhagens culminaria, no final dos anos 1970, na crítica ampla à filosofia científica centrada na epistemologia (Rorty 1979), na solidariedade com os pluralistas amotinados no encontro da APA em 1979 e na sua posição de figura central do movimento pós-analítico na filosofia norte-americana nos anos 1980.

\section{Conclusão}

O diagnóstico de crise da filosofia analítica que Rorty elabora entre o final dos anos 1960 e o início dos anos 1980 (RoRTY 1967, 1979 e 1982) é um exemplo do que Hargens e Kelly-Wilson (1994) chamam de "insatisfação disciplinar" - a percepção de que um campo disciplinar está estagnado - e deve ser compreendido simultaneamente a partir de três pontos de vista distintos. Em um primeiro nível, trata-se de uma crítica filosófica strictu sensu, elaborada por um representante das novas gerações intelectuais a partir de e contra a herança intelectual das gerações anteriores, e nesse sentido é um evento recorrente na dinâmica de mudança das ideias filosóficas em consequência da passagem de gerações intelectuais; em um segundo nível, é reflexo de um "clima de época" (os "anos 1960") marcado pela crítica às hierarquias de toda ordem, mas especialmente acadêmica, e aos monopólios do saber, duas características que associamos ao "pensamento 68" (FERRY e RENAUT 1988); e num terceiro nível, a que demos ênfase neste artigo, é efeito das transformações nas bases materiais da vida filosófica e nas instituições da vida profissional, que passam, conforme mostramos, por

TOLEDO JÚNIOR, Joaquim Elói Cirne de. Richard Rorty e a emergência da filosofia pós-analítica nos Estados Unidos: transformações institucionais e crise disciplinar, 1970-1980. Griot : Revista de Filosofia, Amargosa/Bahia, v.17, n.1, p.377-397, junho/2018. 
um amplo processo de transformação, da expansão dos anos 1950-60 à crise de estagnação e saturação dos anos 1970. Simultaneamente crítica intelectual e bandeira político-institucional, a filosofia pós-analítica emergiu como um movimento intelectual contencioso (FRICKEL e GROSS 2005) que foi sintoma da crise de hegemonia das redes intelectuais que sustentaram, por meio de batalhas intelectuais e institucionais, a filosofia analítica como único estilo filosófico legítimo entre os anos 1930 e 1950 nos Estados Unidos.

TOLEDO JÚNIOR, Joaquim Elói Cirne de. Richard Rorty e a emergência da filosofia pós-analítica nos Estados Unidos: transformações institucionais e crise disciplinar, 1970-1980. Griot : Revista de Filosofia, Amargosa/Bahia, v.17, n.1, p.377-397, junho/2018. 


\section{Referências bibliográficas}

APEL, K. O. Towards a transformation of philosophy. Tradução de Adey, G. e Fisby, D. Milwakee: Marquette University Press, [1973] 1998

BOURDIEU, P. L'ontologie politique de Martin Heidegger. Paris: Editions de Minuit, 1977.

BOURDIEU, P. Homo Academicus. Trad. Peter Collier. Palo Alto: Stanford University Press, 1990.

BURT, R. S. Structural holes and good ideas. American journal of sociology vol. 110, no. 2, pp. 349-399, 2004.

CAMPBELL, J. A thoughtful profession. The early years of the American Philosophical Association. Chicago: Open Court, 2006.

COLLINS, R. For a sociological philosophy. Theory and society, vol. 17 no. 5, 99. 669$702,1988$.

COLLINS, R. The sociology of philosophies: a global theory of intellectual change. Cambridge: Harvard University Press, 1998.

CUSSET, F. French theory: how Foucault, Derrida, Deleuze \& Co. transformed the intellectual life of the United States. Minneapolis: University of Minnesota Press, 2008.

DANTO, A. C. Philosophy as/and/of literature. Proceedings and addresses of the American Philosophical Association, vol. 58, no. 1, setembro de 1984.

FEYERABEND, P. Against method. Londres: New Left Books, 1975.

FRICKEL, S. e GROSS, N. A general theory of scientific/intellectual movements. American sociological review, vol. 70, no. 2, pp. 204-232, 2005.

GEIGER, R. L. Demography and curriculum: the humanities in higher education from the 1950s through the 1980s. In Hollinger. D. A. (org.) The humanities and the dynamics of inclusion since World War II. Baltimore: The Johns Hopkins University Press, 2006.

GRAHAM, H. D. e DIAMOND, N. The rise of American research universities: elites and challengers in the postwar era. Baltimore: The Johns Hopkins University Press, 1997.

HABERMAS, J. The theory of communicative action, volume 1: Reason and the rationalization of society. Tradução de Thomas McCarthy. Boston: Beacon Press, [1981] 1985.

HARGENS, K. V. e KELLY-WILSON, L. Determinants of disciplinary discontent. Social forces 71(3): 603-627, 1994.

HOLLINGER, D. A. Introduction. In Idem (org.). The humanities and the dynamics of inclusion since World War II. Baltimore: The Johns Hopkins University Press, 2006.

JENKS, C. e RIESMAN, D. The academic revolution. Nova York: Doubleday, 1968. KUHN, T. The structure of scientific revolutions. Chicago: University of Chicago Press, [1962] 2012.

KUKLICK, B. A history of philosophy in America, 1720-2000. Oxford: Oxford University Press, 2000.

LAMONT, M. How to become a dominant French philosopher: the case of Jacques Derrida. American journal of sociology, vol. 93, no. 3, pp. 584-622, 1987.

TOLEDO JÚNIOR, Joaquim Elói Cirne de. Richard Rorty e a emergência da filosofia pós-analítica nos Estados Unidos: transformações institucionais e crise disciplinar, 1970-1980. Griot : Revista de Filosofia, Amargosa/Bahia, v.17, n.1, p.377-397, junho/2018. 
LYOTARD, J.- F. La condition postmoderne: rapport sur le savoir. Paris: Éditions de Minuit, 1979.

NOZICK. R. Anarchy, state and utopia. Nova York: Basic Books, 1974.

PUTNAM, H. After empiricism. In RAJCHMAN, J. e WEST, C. Post-analytic philosophy. Nova York: Columbia University Press, 1985.

QUINE, W. V. O. Two dogmas of empiricism. Philosophical review 60, pp. 20-43, 1951.

RAJCHMAN, J. e WEST, C. Post-analytic philosophy. Nova York: Columbia University Press, 1985.

RAWLS, J. A theory of justice. Cambridge: Harvard University Press, 1971.

RINGER, F. The decline of the German mandarins: the German academic community, 1890-1933. Hanover, New Hampshire: University Press of New England, [1968] 1990.

RORTY, R. Metaphilosophical difficulties of linguistic philosophy. In The linguistic turn. Rorty, R. (ed.). Chicago: The University of Chicago Press, 1967.

RORTY, R. Philosophy and the mirror of nature. Nova Jersey: Princeton University Press, 1979.

RORTY, R. Consequences of pragmatism: essays 1972-1980. Minneapolis: Minnesota University Press, 1982.

SCHORSKE, C. E. The new rigorism in the human sciences, 1940-1960. Daedalus, vol. 126, no. 1. American academic culture in transformation: fifty years, four disciplines, pp. 289-309, 1997.

SELLARS, W. Empiricism and the philosophy of mind. Cambridge: Harvard University Press, [1956] 1997.

TOLEDO, J. E. C. de. Richard Rorty e a emergência da filosofia analítica: transformações institucionais e mudança intelectual na filosofia profissional norteamericana contemporânea. Tese de doutorado. Campinas: Unicamp, 2015.

WITTGensteIN, L. Philosophical investigations. Tradução de G. E. M. Anscombe. Londres: Macmillian Co, 1969.

Autor(a) para correspondência: Joaquim Elói Cirne de Toledo Júnior, Universidade de São Paulo, Faculdade de Filosofia, Letras e Ciências Humanas, R. do Lago, 717 - Butantã, CEP 03178-200, São Paulo - SP, Brasil. joaquim.toledo.jr@gmail.com

TOLEDO JÚNIOR, Joaquim Elói Cirne de. Richard Rorty e a emergência da filosofia pós-analítica nos Estados Unidos: transformações institucionais e crise disciplinar, 1970-1980. Griot : Revista de Filosofia, Amargosa/Bahia, v.17, n.1, p.377-397, junho/2018. 